\title{
Special Event of Interest Document
}

National Cancer Institute

\section{Source}

National Cancer Institute. Special Event of Interest Document. NCI Thesaurus. Code C115558.

Records of an event experienced by a subject in a clinical trial, which is defined by the clinical study protocol as significant. 